\title{
Multiphasic screening of priority chemical compounds in drinking water by process control and human health risk
}

Yan Liu ${ }^{1,2}$, Xue Li ${ }^{1,2}$, Xiaocui Qiao ${ }^{1,2}$, Xingru Zhao ${ }^{1,2}$, Simin Ge ${ }^{1,2}$, Haiyan Wang ${ }^{1,2^{*}}$ and Dan $\mathrm{Li}^{1,2^{*}}$ (D)

\begin{abstract}
Background: The residual chemical pollutants in drinking water may cause adverse effects on human health. Chemical compounds potentially affecting human health have been widely explored, while the multiphasic evaluation of chemical compounds by process control and human health risk is still rarely reported. In the present study, we used multiphasic criteria to assess the health risk including effluent concentration, accumulation index, purification index for the removal efficiency during the drinking water treatment processes, carcinogen classification based on the International Agency for Research on Cancer standards, non-carcinogenic health hazards and carcinogenic risk.

Results: Among the monitored chemicals, 47 and 44 chemical compounds were detected in raw water and treated water, respectively. The generation and removal of chemical compounds implied that the migration and transformation of chemicals during the purification processes affected the effluent concentration, posing a direct potential health risk. Of these compounds, 41 contaminants' profiles were screened as priority chemical compounds (PCCs).

Conclusions: The top eight PCCs with high carcinogenic risk were highlighted. Some effective steps, such as protecting the raw water sources, improving the removal performance and reducing the disinfection by-products during the purification process by introducing advanced treatment technologies, were suggested to maintain drinking water security. Collectively, our findings provided novel scientific supports for the sustainable management of drinking water to promote human health.
\end{abstract}

Keywords: Drinking water security, Multiphasic assessment, Carcinogenic health hazard, Rank assignment method, Source water protection, Sustainable management

\section{Graphical Abstract}

\section{Background}

Drinking water security (DWS) has become a critical international issue since approximately $80 \%$ of diseases result from contaminated drinking water as reported by the World Health Organization (WHO) $[1,2]$. The water containing chemical compounds poses serious threats to

\footnotetext{
*Correspondence: wanghy@craes.org.cn; lidan01@craes.org.cn ${ }^{1}$ Environmental Standard Institute, Ministry of Ecology and Environment of the People's Republic of China, Chinese Research Academy of Environmental Sciences, 100012 Beijing, China

Full list of author information is available at the end of the article
}

water environment sustainability, ecosystem health, and DWS [3-5]. The priority chemical compounds (PCCs), characterized by wide distribution and high toxicity, are refractory with long residue times [6, 7]. PCCs can enter biological organisms and tissues through exposure and food chain accumulation, and then affect the normal physiological functions of the organism through biochemical or physicochemical effects, threatening human health [8-10].

With the advancement of monitoring technology and toxicological studies on the chemicals, emerging 
contaminants in the drinking water, such as heavy metals, volatile organic compounds (VOCs), polychlorinated biphenyls (PCBs), organophosphorus pesticides (OPPs), and organochlorine pesticides (OCPs), are being concerned $[11,12]$. Consequently, it becomes a worldwide problem for the management of the government sector in the screening of PCCs. A majority of chemical substances with relatively low concentrations in fine fresh surface water can be removed via the purification process in drinking water treatment plants (DWTPs), while some chemicals can be generated through the degradation, biosynthesis and accumulation during the water purification processes owing to the limitations of water purification technologies in the utilities of DWTPs [13]. For example, some of these chemicals can be re-released due to membrane pollution in the treatment processes [14]. In particular, the final step, which involves the disinfection procedure for protecting drinking water against external contamination and regrowth of bacteria, can generate approximately 600-700 chemical by-products [15]. Process control of purification procedures (i.e., flocculation, coagulation, sedimentation, adoption, filtration, disinfection or oxidation processes) from raw water source to treated drinking water provides technical support for the management of DWTPs $[16,17]$. Therefore, monitoring the concentrations of chemical compounds in source water and identifying the removal effect of drinking water purification processes (that is the dynamics of chemical compounds from raw water source to treated drinking water) are two important factors in the assessment of drinking water.

However, the above-mentioned contaminants in the drinking water generally pose a potential risk for human health for a long-term drinking exposure. Besides, few studies have been conducted to assess above-mentioned two aspects in the screening of optimal control pollutants [18-20]. With the growing demand for safe drinking water, it is imperative to screen multiphasic criteria characterized by process control and health risk based on the on-site investigation, which will provide a critical perspective for the screening of PCCs, strengthening the process control during the drinking water treatment and improving the sustainable management of DWS [21, 22]. Such evaluation would also fill the gaps between human health and public utilities through the management of drinking water.

In the present study, 283 water samples of raw water and treated water from 146 DWTPs were collected to identify the effects of drinking water purification processes, and 76 chemical compounds were monitored to assess and screen PCCs by process control and health risk. This work aimed to (1) analyze the occurrence and concentration distribution of chemical compounds in the influent and effluent from 146 DWTPs; (2) emphasize the removal and generation processes during the purification procedure; (3) assess the health risk of chemical compounds in the influent and effluent using the hazard index (HI) and carcinogenic risk (CR); and (4) select PCCs by using the rank assignment method for the sustainable management of DWS.

\section{Materials and methods Distributions of DWTPs}

In the present study, 140 water samples from the influent (raw water) and 143 water samples from the effluent (treated water for drinking) were collected from 146 DWTPs located in 24 cities in the seven major river basins of China, including the Songhuajiang River, Liao River, Huai River, Yellow River, Hai River, Yangtze River, and Pearl River. The water supply capacity for each DWTP was more than 1000 tons/day water and the service population is more than 10,000 persons. More detailed information is provided in Additional file 1: Table S1. Figure 1 shows the geographic information for sampling sites covering 24 cities and 146 DWTPs.

All collected water samples were stored in a portable cooler with dry ice and immediately transported to the laboratory for analysis. A total of 76 chemical compounds, including heavy metals, VOCs, PCBs, OPPs, and OCPs, were monitored and analyzed.

The presence of heavy metals was determined using atomic absorption spectroscopy. Other compounds were determined via spectrophotometry, headspace gas chromatography (HS GC), solid-phase extraction gas chromatography (SPE GC), high-performance liquid chromatography (HPLC), and ultra-performance liquid chromatography (UPLC). Details on the compounds and analytic methods were provided in Additional file 1: Table S2.

\section{Multiphasic evaluation analysis}

Given the urgent requirements of environmental sustainability, safe drinking water, and human health, the concentrations of the chemical compounds, classification of carcinogens based on the International Agency for Research on Cancer (IARC) standards, accumulation index $(A I)$, carcinogenic risks $(C R)$, and hazard index $(H I)$ were selected as the multiphasic evaluation variables (Fig. 2). The water treatment processes at the DWTPs were found to produce by-products, and health risk was generally a result of the exposure concentration of the treated water. Therefore, a novel and simple rank assignment method was established based on on-site investigations of concentration, technological developments and health risk. 


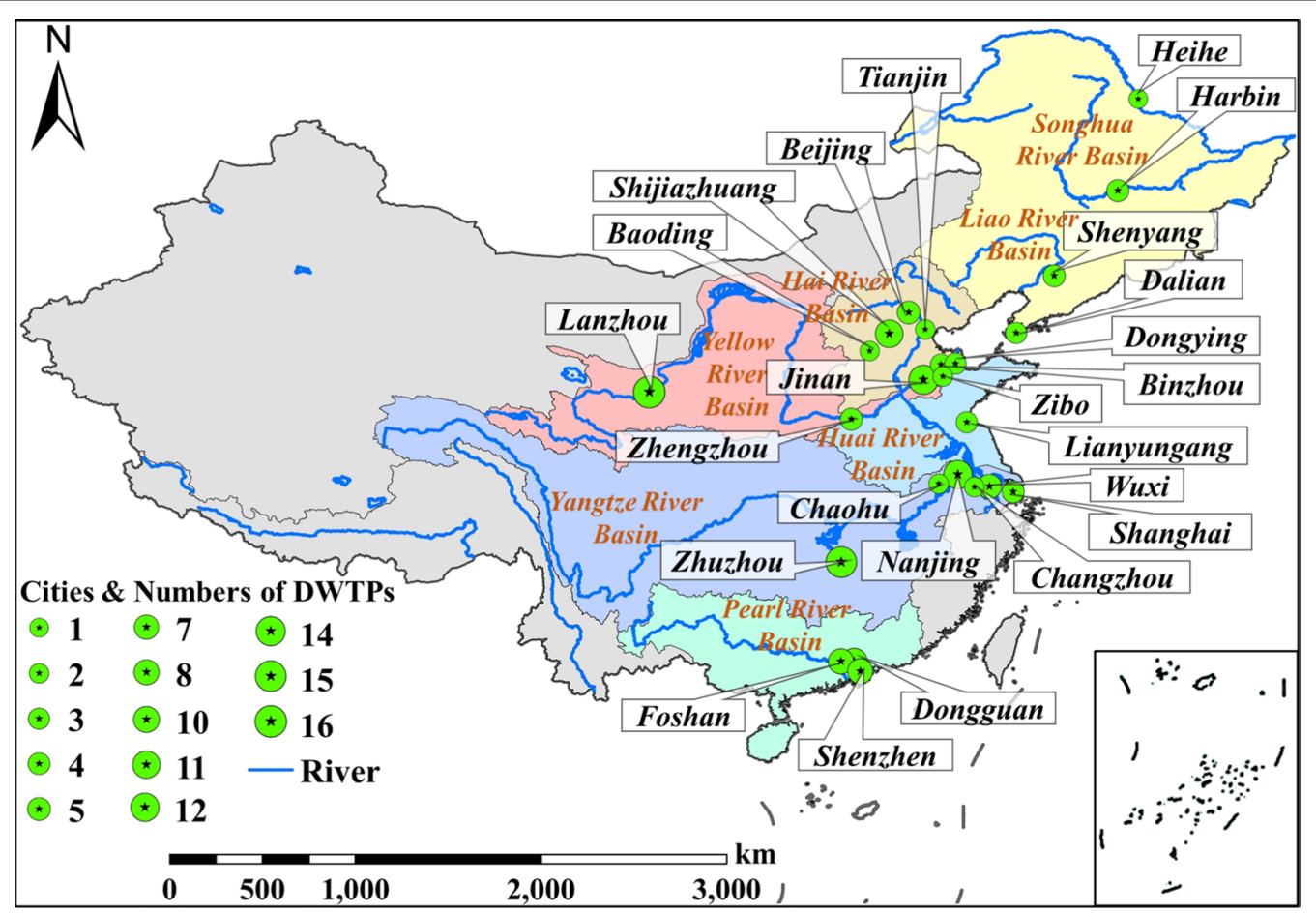

Fig. 1 Distribution of the 24 sampling cities, covering the 146 drinking water treatment plants investigated in this study

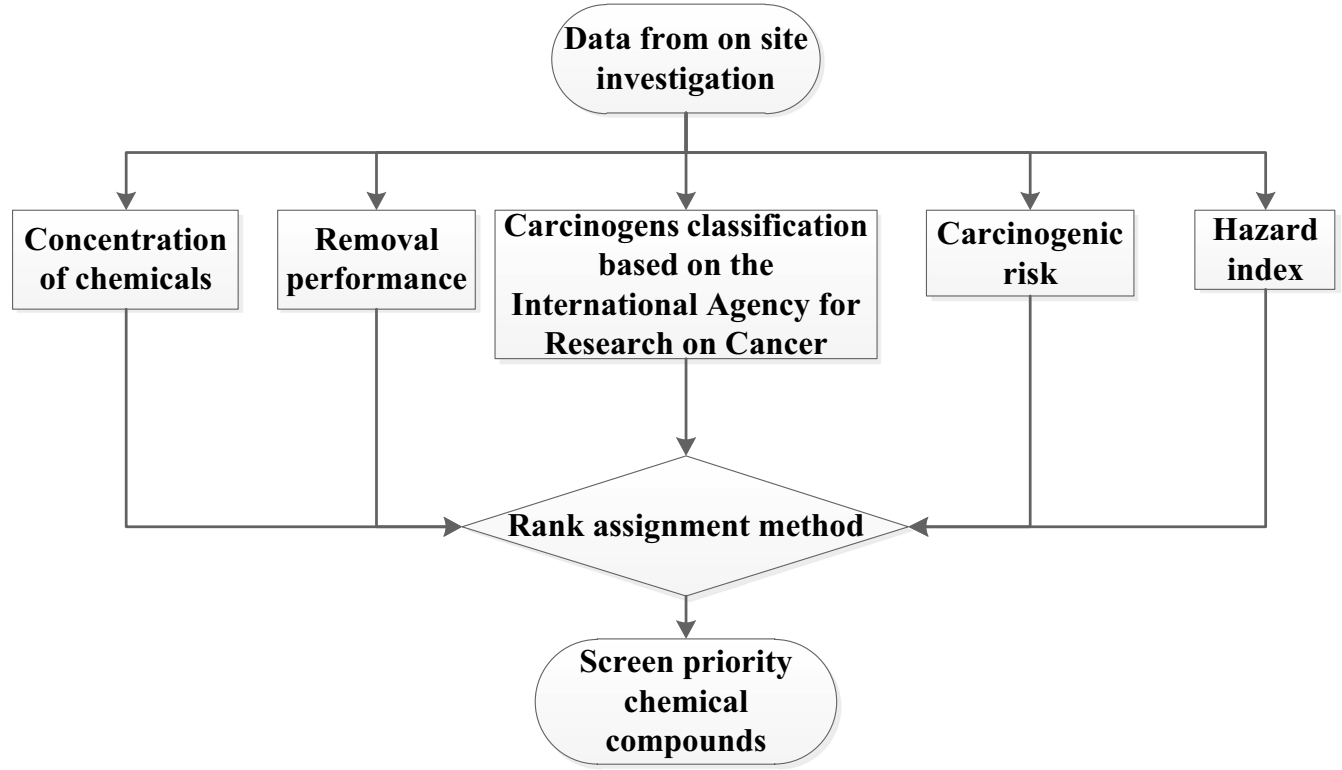

Fig. 2 The flowchart of rank assignment system for the screening of chemical compounds

This method was established to avoid human impacts when screening PCCs (Table 1). The concentration rank was assigned according to the pollutants concentrations. In general, when $C_{\mathrm{i}}$ was greater than the standard concentration [23], the pollutant was considered to be safe. The carcinogenic rank was assigned according to the IARC classification [24, 25]. The $H I$ and $C R$ ranks were assigned through sequential data analysis. When 
Table 1 Rank assignment method used for screening the chemical compounds

\begin{tabular}{lllll}
\hline & No & Low & Moderate & High \\
\hline Concentration & $C_{i} \leq 0.1 C_{s}$ & $0.1 C_{s}<C_{i} \leq 0.5 C_{s}$ & $0.5 C_{s}<C_{i} \leq C_{s}$ & $C_{i}>C_{s}$ \\
Accumulation index & $A l \leq 0$ & $0<A l \leq 25 \%$ & $25 \%<A l \leq 50 \%$ & $A l>50 \%$ \\
Purification index & 3 & $2 B$ & $2 A$ & 1 \\
Hazard index & $H I \leq 0.01$ & $0.01<H I \leq 0.1$ & $0.1<H I \leq 1$ & $H I>1$ \\
Carcinogenic risk & $C R \leq 10^{-6}$ & $10^{-6}<C R \leq 10^{-5}$ & $10^{-5}<C R \leq 10^{-4}$ & $C R>10^{-4}$ \\
\hline
\end{tabular}

$H I<1.00$, the pollutant was considered to pose no significant risk of non-carcinogenic effects [26]. When $C R<10^{-6}$, the carcinogenic risk of the pollutant was acceptable and considered a low risk to human health, whereas the carcinogenic risk was unacceptable when $C R>10^{-4}$ [27]. Particularly, when the SF values of pollutants could not be obtained, the rank assignment was conducted based on the IARC classification. Missing data were recorded as moderate or low, dependent on the specific characteristics of the chemical compounds (as the IARC guidelines). This multiphasic screening method also avoided significant human error caused by the selection of weight coefficients in the weight assignment method. The intuitive and simple evaluation analysis reflected the possible problems on human health risk in the processes from raw water protection to the treated drinking water, providing multiphasic management suggestions for DWS.

\section{Data statistics}

The detection rate $(D R)$, excess rate $(E R)$, removal efficiency $(R E), A I$, and purification index $(P I)$ were calculated as follows:

$$
\begin{aligned}
& D R=\frac{n}{N} \times 100 \%, \\
& E R=\frac{n_{\mathrm{e}}}{N} \times 100 \%, \\
& R E=\frac{\left(C_{\mathrm{i}}-C_{\mathrm{o}}\right)}{C_{\mathrm{i}}} \times 100 \%, \\
& A I=\frac{n_{\mathrm{a}}}{N_{\mathrm{RE}}} \times 100 \%, \\
& P I=\frac{n_{\mathrm{p}}}{N_{\mathrm{RE}}} \times 100 \%,
\end{aligned}
$$

where $n, n_{\mathrm{e}}$, and $N$ are the number of samples detected, the number of samples exceeding the standard concentration, and the total number of water samples collected, respectively; $C_{\mathrm{i}}$ and $C_{\mathrm{o}}$ are the chemical compound concentrations in the influent and effluent $(\mathrm{mg} / \mathrm{L})$, respectively; $n_{\mathrm{a}}$ is the number of sample pairs where $\mathrm{RE}<0 ; n_{\mathrm{p}}$ is the number of sample pairs where $R E \geq 0$; and $N_{\mathrm{RE}}$ is the number of sample pairs where the $R E$ value was available.

\section{Health risk assessment}

The health risk of drinking water is directly related to oral ingestion. The method developed by the USEPA was used in this study to assess the health risk associated with the ingestion of various chemical compounds [13, 28]. The chronic daily intake (CDI, $\mathrm{mg} / \mathrm{kg}$ day) via the ingestion of pollutants in drinking water is typically used for health risk assessment, which was calculated as follows:

$$
C D I=\frac{C_{\mathrm{o}} \times D I R \times E F \times E D}{B W \times A T},
$$

where $C_{\mathrm{o}}$ is the pollutant concentration in the effluent $(\mathrm{mg} / \mathrm{L}), D I R$ is the daily ingestion rate of drinking water (L/day), which typically has a value of $2 \mathrm{~L} /$ day, $E F$ is the exposure frequency (day/year), which is typically equal to 365 days/year, $E D$ is the exposure duration (year), which is set as 30 years for non-carcinogens and 70 years for carcinogens, $B W$ is the body weight $(\mathrm{kg})$, with a standard value of $70.0 \mathrm{~kg}$, and $A T$ is the average exposure period (days), with typical values of $30 \times 365$ days for non-carcinogens and $70 \times 365$ days for carcinogens. The $C R$ and $H I$ of the pollutants were calculated as follows:

$$
\begin{aligned}
& H I=\frac{C D I}{R f D}, \\
& C R=C D I \times S F,
\end{aligned}
$$

where $R f D$ is the reference dose for toxic pollutants $(\mathrm{mg} /$ $\mathrm{kg}$ day) and $S F$ is the pollutant slope factor ( $\mathrm{kg}$ day $/ \mathrm{mg})$. Both the RfD and $S F$ were collected from the websites of the US Integrated Risk Information System (IRIS) and USEPA. 


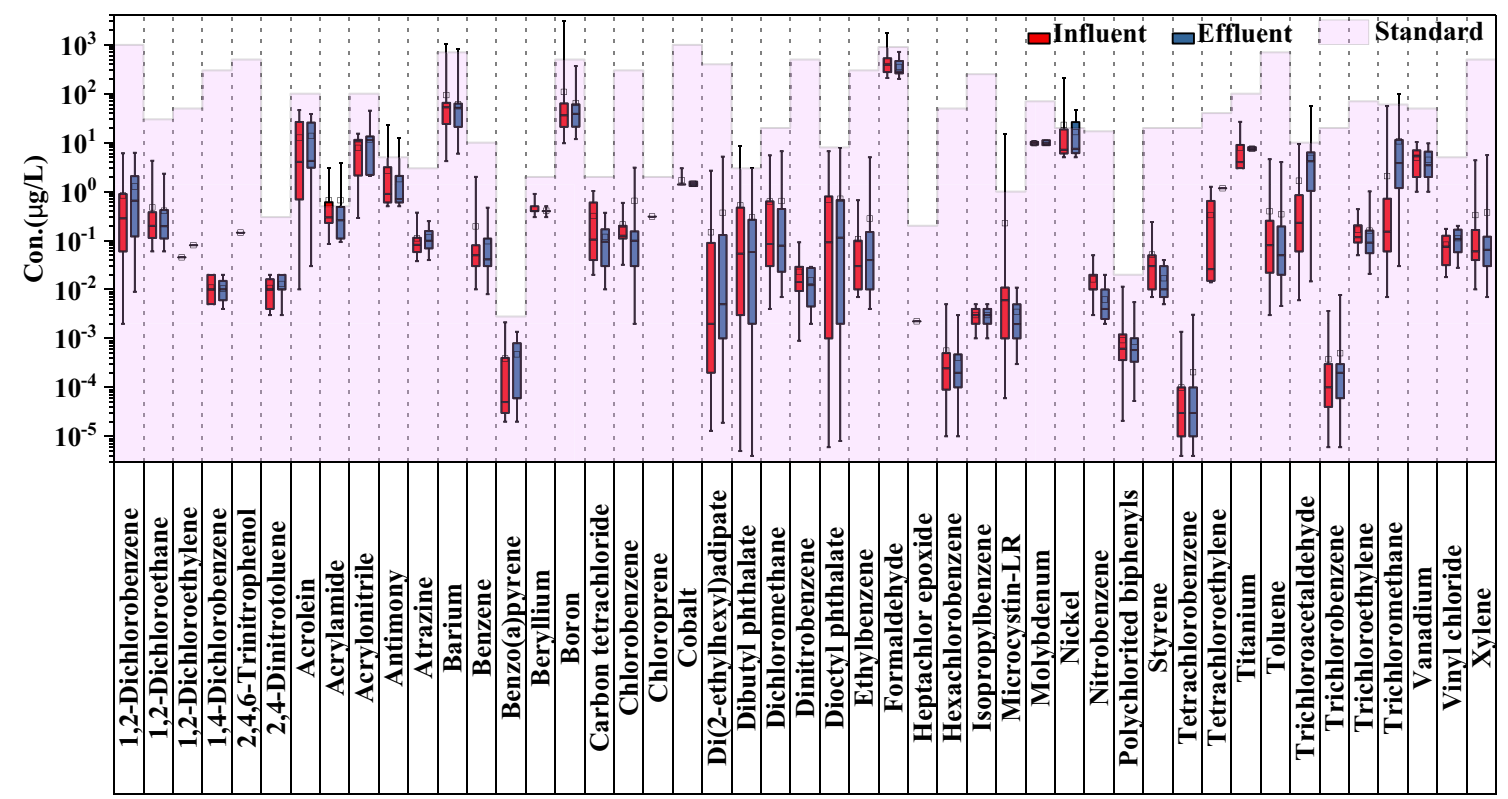

Fig. 3 The concentration of chemical compounds in the influent and effluent

\section{Results and discussion}

\section{Distribution of chemical compounds}

Among the 76 target chemical compounds, 47 chemical compounds in the influent and 44 chemicals in the effluent were detected (Fig. 3). Specifically, only two pesticides, heptachlor epoxide and atrazine, were detected with low concentrations of $0.00224 \mu \mathrm{g} / \mathrm{L}$ and $0.038 \sim 0.374 \mu \mathrm{g} / \mathrm{L}$ in the influent, respectively, indicating that pesticides were minor pollutants in drinking water sources. The observed pesticide concentrations were lower compared with previous report [29]. Tetraethyl lead and methylmercury, two well-known metalorganic compounds, characterized by high risk, were undetectable.

Table 2 lists the compounds detected in the water samples. The $D R$ values of 10 chemical compounds in the influent were more than $50 \%$, including $\mathrm{Ba}(99.3 \%)$, dibutyl phthalate (92.1\%), dioctyl phthalate (91.4\%), polychlorinated biphenyls (81.4\%), di(2-ethylhexyl) adipate $(59.3 \%)$, trichlorobenzene $(57.9 \%)$, dichloromethane $(55.0 \%)$, dichloromethane $(53.6 \%)$, microcystin-LR (50.7\%), and 1,2-dichloroethane (50.7\%). The results suggested that these pollutants were widely distributed, which were consistent with their global distributions [18, 30, 31]. More detailed informations were provided in Additional file 1: Tables S3 and S4.

The concentrations of chemical compounds in the influent differed from those in the effluent (Fig. 3). The concentration of eight chemical compounds $(\mathrm{Sb}, \mathrm{B}, \mathrm{Ni}$, $\mathrm{Ba}$, acrylamide, dibutyl phthalate, microcystin-LR, and formaldehyde) in the influent exceeded the standard values [17], while the concentrations of seven chemicals $(\mathrm{Sb}$, $\mathrm{Ni}, \mathrm{Ba}$, acrylamide, dibutyl phthalate, trichloroacetaldehyde and trichloromethane) in the effluent were higher compared with the standard values.

DWTPs with exceedingly high concentrations of $\mathrm{Ba}$ were located at Binzhou City, Dongying City, and Zibo City in the Yellow River basin owing to the high background values of the compounds in the local soil [32]. DWTPs, where the $\mathrm{Ni}$ concentrations exceeded the standard value, were located in the Hai River basin, owing to the high background values of $\mathrm{Ni}$ compounds in the local soil as well as the excessive compound discharge from local chemical enterprises [33]. Liang et al. [34] have shown that the maximum concentrations of $\mathrm{Sb}$, $\mathrm{Ni}$ and $\mathrm{Ba}$ in the Jiulongjiang River in Southeast China are $9.67 \mu \mathrm{g} / \mathrm{L}, 10.05 \mathrm{ug} / \mathrm{L}$ and $231.42 \mu \mathrm{g} / \mathrm{L}$, respectively, while Wu et al. [35] have shown that the maximum concentration of $\mathrm{Sb}, \mathrm{Ni}$ and $\mathrm{Ba}$ from rural areas of China are $0.653 \mu \mathrm{g} / \mathrm{L}, 15.2 \mu \mathrm{g} / \mathrm{L}$ and $384 \mu \mathrm{g} / \mathrm{L}$, respectively. All of these values are lower compared with our results $(12.5 \mu \mathrm{g} / \mathrm{L}, 212 \mu \mathrm{g} / \mathrm{L}$ and $1060.7 \mu \mathrm{g} / \mathrm{L}$, respectively). These differences resulted from various factors, such as different compound background values, local variations of discharge, and removal performance of different treatment processes, as well as the degradation rate of chemical compounds during the water plant treatment processes [18, 36-38]. Additional file 1: Table S5 provided more detailed information. 
Table 2 Detected chemical compounds in the influent and effluent

\begin{tabular}{|c|c|c|c|c|}
\hline & Influent & & Effluent & \\
\hline & $\begin{array}{l}\text { Detection } \\
\text { number }\end{array}$ & $D R(\%)$ & $\begin{array}{l}\text { Detection } \\
\text { number }\end{array}$ & $D R(\%)$ \\
\hline Barium & 139 & 99.3 & 140 & 97.9 \\
\hline Dibutyl phthalate & 129 & 92.1 & 138 & 96.5 \\
\hline Dioctyl phthalate & 128 & 91.4 & 131 & 91.6 \\
\hline Polychlorinated biphenyls & 114 & 81.4 & 108 & 75.5 \\
\hline Di(2-ethylhexyl)adipate & 83 & 59.3 & 100 & 69.9 \\
\hline Trichlorobenzene & 81 & 57.9 & 82 & 57.3 \\
\hline Dichloromethane & 77 & 55 & 79 & 55.2 \\
\hline Trichloromethane & 75 & 53.6 & 128 & 89.5 \\
\hline Microcystin-LR & 71 & 50.7 & 21 & 14.7 \\
\hline 1, 2-Dichloroethane & 71 & 50.7 & 70 & 49 \\
\hline Hexachlorobenzene & 66 & 47.1 & 69 & 48.3 \\
\hline Boron & 65 & 46.4 & 64 & 44.8 \\
\hline Toluene & 56 & 40 & 52 & 36.4 \\
\hline Tetrachlorobenzene & 47 & 33.6 & 51 & 35.7 \\
\hline Trichloroacetaldehyde & 46 & 32.9 & 95 & 66.4 \\
\hline Benzene & 45 & 32.1 & 41 & 28.7 \\
\hline Vanadium & 44 & 31.4 & 31 & 21.7 \\
\hline 1,2-Dichlorobenzene & 44 & 31.4 & 48 & 33.6 \\
\hline Xylene & 40 & 28.6 & 35 & 24.5 \\
\hline Acrolein & 31 & 22.1 & 28 & 19.6 \\
\hline Formaldehyde & 30 & 21.4 & 15 & 10.5 \\
\hline Atrazine & 29 & 20.7 & 24 & 16.8 \\
\hline Antimony & 26 & 18.6 & 24 & 16.8 \\
\hline Ethylbenzene & 24 & 17.1 & 26 & 18.2 \\
\hline Nickel & 23 & 16.4 & 20 & 14 \\
\hline Trichloroethylene & 19 & 13.6 & 21 & 14.7 \\
\hline Beryllium & 14 & 10 & 14 & 9.8 \\
\hline 2,4-Dinitrotoluene & 13 & 9.3 & 21 & 14.7 \\
\hline Dinitrobenzene & 12 & 8.6 & 12 & 8.4 \\
\hline Titanium & 11 & 7.9 & 2 & 1.4 \\
\hline Styrene & 10 & 7.1 & 6 & 4.2 \\
\hline Acrylonitrile & 10 & 7.1 & 10 & 7 \\
\hline Chlorobenzene & 9 & 6.4 & 9 & 6.3 \\
\hline Acrylamide & 9 & 6.4 & 14 & 9.8 \\
\hline Vinyl chloride & 8 & 5.7 & 8 & 5.6 \\
\hline Carbon tetrachloride & 8 & 5.7 & 16 & 11.2 \\
\hline Benzo(a)pyrene & 8 & 5.7 & 9 & 6.3 \\
\hline Nitrobenzene & 7 & 5 & 16 & 11.2 \\
\hline 1, 4-Dichlorobenzene & 7 & 5 & 7 & 4.9 \\
\hline Isopropylbenzene & 6 & 4.3 & 4 & 2.8 \\
\hline Cobalt & 5 & 3.6 & 4 & 2.8 \\
\hline Molybdenum & 4 & 2.9 & 3 & 2.1 \\
\hline Tetrachloroethylene & 4 & 2.9 & 1 & 0.7 \\
\hline Heptachlor epoxide & 1 & 0.7 & nd & nd \\
\hline Chloroprene & 1 & 0.7 & nd & nd \\
\hline 1,2-Dichloroethylene & 1 & 0.7 & 1 & 0.7 \\
\hline 2,4,6-Trinitrophenol & 1 & 0.7 & nd & nd \\
\hline
\end{tabular}

nd means no detection
High concentrations of dibutyl phthalate and acrylamide appeared in the Yangtze River basin, which was mainly attributed to the accumulation of chemical compounds during the water treatment processes in DWTPs [39-41]. Microplastics act as vectors for contaminants including dibutyl phthalate and acrylamide, which are difficult to remove in the DWTPs [42]. The same result has been reported by Koelmans et al. [43] that higher concentrations in the effluent probably reflect the retention of microplastics. High concentrations of trichloroacetaldehyde and trichloromethane in the effluent were generally caused by the chlorine disinfection procedure, with the excess rates of $3.50 \%$ and $2.10 \%$, respectively. The above-mentioned chemicals indicated that the treatment processes affected the concentrations of chemical compounds in the effluent, posing a direct risk to human health for long-term drinking exposure [44].

\section{Removal and generation of chemical compounds}

The treatment processes play a pivotal role in water purification since they influence the chemical compounds composition via chemical removal and generation. Removal and generation of various chemicals via different processes were characterized by $A I$ and $P I$ values (Fig. 4). The $A I$ values were closely linked to the generation and accumulation of chemicals, and the PI values were associated with the removal characteristics of chemicals in the purification treatment process.

The results showed that metal compounds $(\mathrm{Ba}, \mathrm{Sb}$, $\mathrm{Be}, \mathrm{Ti}$, and $\mathrm{V}$ ) were easily removed in the DWTPs. Ion exchange technology and adsorption are commonly used for the intensive purification of drinking water, thus cationic metal compounds are easily removed during the treatment processes [26]. Certain organic compounds, including acrolein, atrazine, benzene, formaldehyde, microcystin-LR, polychlorinated biphenyls, toluene, xylene, and 2,4,6-trinitrophenol are also easily removed in the purification processes. These substances are easily transformed, degraded, or removed by different processes, including adsorption, microbial action, disinfection, and the use of ozone and associated oxidation processes $[19,20,45,46]$.

Nevertheless, certain volatile halohydrocarbons, including 1,2-dichloroethane, carbon tetrachloride, trichloromethane, and some benzenecontaining compounds including 1,2-dichlorobenzene, 2,4-dinitrotoluene, nitrobenzene, trichlorobenzene, dibutyl phthalate, and dioctyl phthalate were difficult to remove via the treatment processes. Especially, chlorinecontaining compounds may be generated or produced due to chlorine disinfection during the treatment process [47-49]. Benzene-containing compounds usually present good stability with refractory biological properties. 


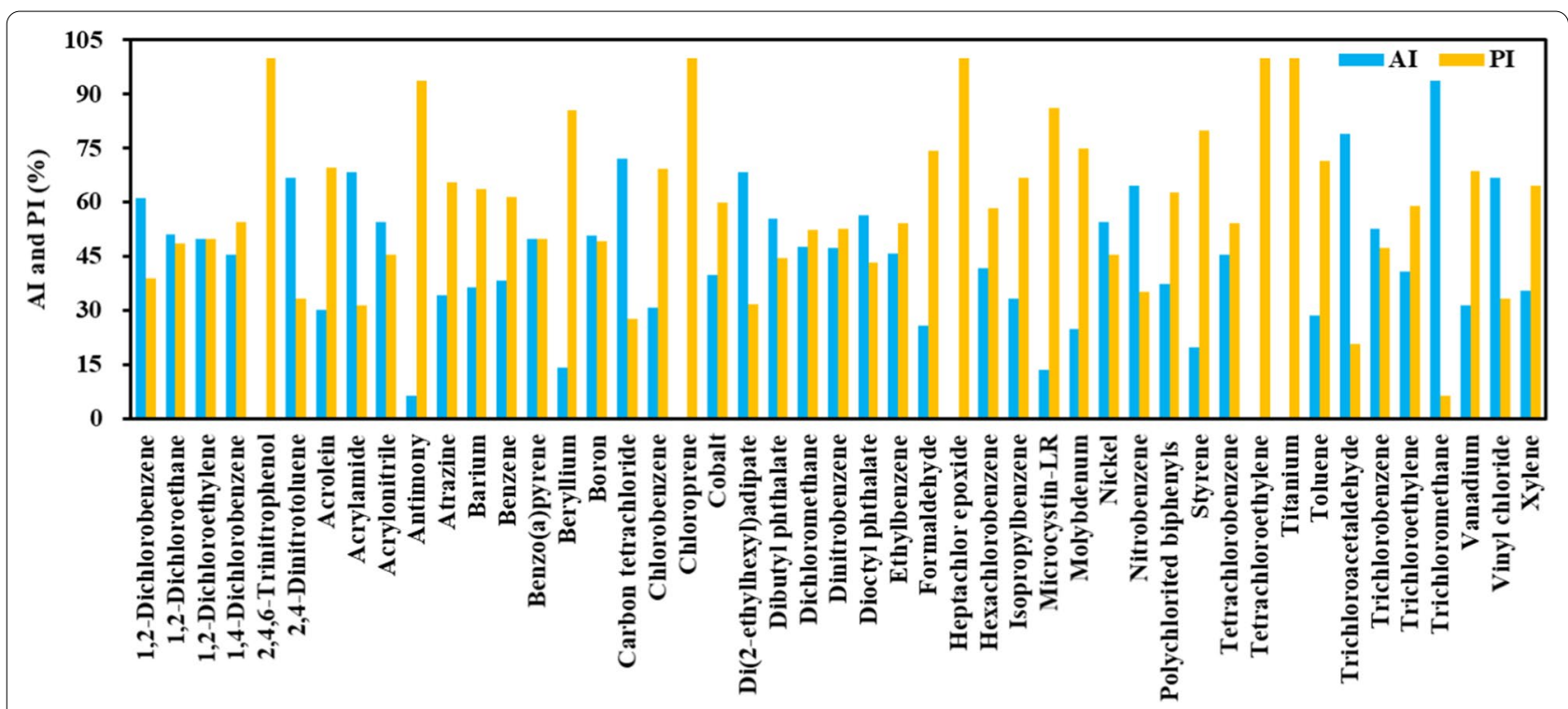

Fig. 4 The $A l$, and Pl of chemical compounds in the influent and effluent

Certain nitro-containing compounds are also difficult to be removed with adsorption or oxidation processes via the purification process $[50,51]$. Trichloroacetaldehyde, (di(2-ethylhexyl)adipate), $\mathrm{Ni}, \mathrm{B}$, acrylamide, and acrylonitrile were also accumulated in the effluent. Free radical substitution reactions easily occur during chlorine or ozone disinfection, which can explain the higher concentrations of trichloroacetaldehyde, trichloromethane, and acrylamide in the effluent [52, 53]. Acrylamide hurts human reproductive organs and neurological systems and it is classified as a $2 \mathrm{~A}$ carcinogen by the IARC [39, 54]. Acrylamide was concentrated in the effluent because (1) the coagulation flocculant (polyacrylamide) commonly used in the treatment process contained acrylamide and acrylonitrile; and (2) acrylamide could also be produced from acrylonitrile with oxidation processes.

Compared with the other compounds, dibutyl phthalate, dioctyl phthalate, and di(2-ethylhexyl)adipate are stable and less polar, which render the removal of those pollutants. The DBPs, usually associated with cancer, pose a serious threat to human health through long-term drinking exposure $[55,56]$. The results illustrated that the concentration changes of chemical compounds in the effluent were linked with their occurrence in the influent. These chemical by-products could be generated through synthesis, transformation, and degradation owing to biochemical or chemical reactions that occurred during the purification and disinfection processes $[57,58]$.

\section{Risk assessment of chemical compounds}

The occurrence and concentration of the respective compounds reflected the environmental impact of the raw water. However, the concentrations of the chemical compounds in the raw water changed during the treatment processes, which altered the concentrations of compounds in the effluent. Figure 5 illustrates that the $H I$ and $C R$ values of detected 47 chemical compounds. The $R F D$ and $S F$ values used to calculate $H I$ and $C R$ values were also presented in Additional file 1: Table S6.

When $H I>1.00$, non-carcinogenic effects were more likely to occur, while $H I<1.00$ indicated no significant risk of non-carcinogenic effects on human health for lifetime exposure. The $H I$ values of acrolein, microcystin-LR, antimony and titanium ranged from $5.7 \times 10^{-4}-2.6, \quad 2.5 \times 10^{-4}-63.5, \quad 3.6 \times 10^{-2}-1.6$ and $0.5-4.8$, respectively, suggesting that a higher $H I$ value increased the occurrence of non-carcinogenic effects [26]. The highest $H I$ values of microcystin-LR occurred in the source water, which illustrated that the concentration of microcystin-LR in the source water should attach much attention. As previously reported, acrolein can cause cellular gene mutation, reduce cell repairability, and harm the retina [59]. Long-time drinking exposure to microcystin-LR can impair the functions of colorectal and liver tissues $[60,61]$. An upper limit concentration of microcystin-LR $(1 \mu \mathrm{g} / \mathrm{L})$ in the drinking water is recommended by WHO [62]. In Ain Zada, the concentrations of microcystin-LR were found in the dam range from $19.6 \mu \mathrm{g} / \mathrm{L}$ in raw water to $6.3 \mu \mathrm{g} / \mathrm{L}$ in drinking water [63]. Wang et al. [64] have shown that 

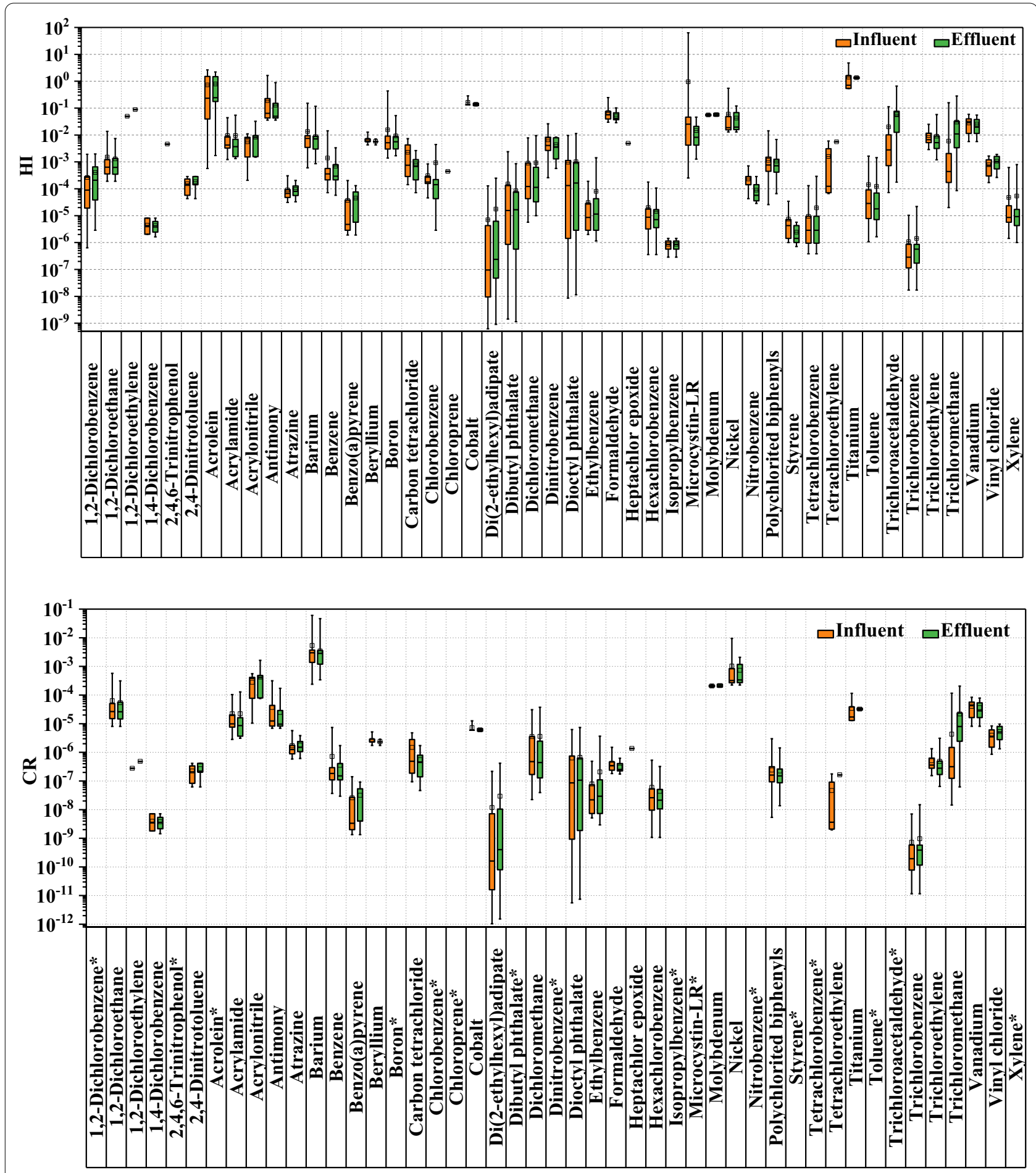

Fig. 5 a The $H I$ and $\mathbf{b} C R$ of the chemical compounds. The SF values for the compounds with "*' were unavailable

the mean microcystin content in lake water is $11.8 \mu \mathrm{g} / \mathrm{L}$ and the maximum concentration reaches as high as $35.8 \mu \mathrm{g} / \mathrm{L}$ during the blooms of cyanobacteria in Taihu Lake, China. A major concentration of microcystin-LR
$(2.1 \mu \mathrm{g} / \mathrm{L})$ in raw water in this study was about seven times higher compared with that in the Amazon River basin $(2.1 \mu \mathrm{g} / \mathrm{L})$ [65]. The maximum microcystinLR concentration in the treated water is $0.1 \mu \mathrm{g} / \mathrm{L}$ in 
Oliveira's survey. The preferable removal performance of microcystin-LR is obtained in the DWTPs in the Amazon River basin, which is consistent with this study. Of note, the maximum $0.011 \mu \mathrm{g} / \mathrm{L}$ of microcystin-LR in the treated water was found in this study. Due to great removal performance for microcystinLR in the DWTPs, the potantial hazard was effectively controlled. Antimony is one of the most concerning global toxic metals, with a maximum concentration of $22.9 \mu \mathrm{g} / \mathrm{L}$ in the influent and $12.5 \mu \mathrm{g} / \mathrm{L}$ in the effluent.

The health risk of these compounds was assessed using the IARC carcinogenicity classification. The IARC carcinogenicity classification for respective compounds was presented in Additional file 1: Table S6. Chloral, styrene, and tetrachlorobenzene have been classified in Group 2A by the IARC, indicating that they are likely carcinogenic to humans. Boron, 1,2-dichlorobenzene, xylene, toluene, and acrolein are listed in Group 3, showing that they are not carcinogenic to humans.

To explore the carcinogenicity for chemicals, the evaluation of $C R$ values in Fig. 5 provided more information. The $C R$ values of 16 chemical compounds were not calculated due to missing $S F$ values. Considering the acceptable range of non-carcinogenic risk $\left(10^{-4}-10^{-6}\right)$ defined by the USEPA, the $C R$ values of 23 chemical compounds were lower than $10^{-4}$ in the effluent, demonstrating that the carcinogenic risk of these compounds was acceptable and the human health risk was very low over a lifetime of exposure. In contrast, eight chemical compounds exhibited high $C R$ values, particularly $\mathrm{Ba}$ $\left(2.4 \times 10^{-4}-6.0 \times 10^{-2}\right)$, Mo $\left(1.9 \times 10^{-4}-2.4 \times 10^{-4}\right)$ and Ni $\left(2.3 \times 10^{-4}-7.5 \times 10^{-3}\right)$. Metal compounds can easily bioaccumulate in the human body, which should be the subject of further investigations. Barium exhibited a relatively low cancer risk. However, it demonstrated one of the highest potential carcinogenic risk for human health in this study due to its high concentration, followed by Mo and $\mathrm{Ni}$, beryllium, formaldehyde, trichloroethylene, vinyl chloride, benzene, and PCBs. These chemicals are classified as Group 1 carcinogens by the IARC, which are carcinogenic to human health even at low concentrations on the order of $\mathrm{ng} / \mathrm{L}$, as reported by $\mathrm{Li}$ et al. [66]. Although these chemical compounds were at low concentrations, high toxicity of chemical compounds can still pose risk to human health. For example, formaldehyde has been proven to be related to leukemia and is widely considered as one of the main factors affecting the human hematopoietic system. The increasing number of private cars, as well as building and decorative materials, has intensified formaldehyde discharge, which threatens the ecosystem and water resource cycle $[67,68]$. Therefore, the carcinogenic risk factor was affected by both

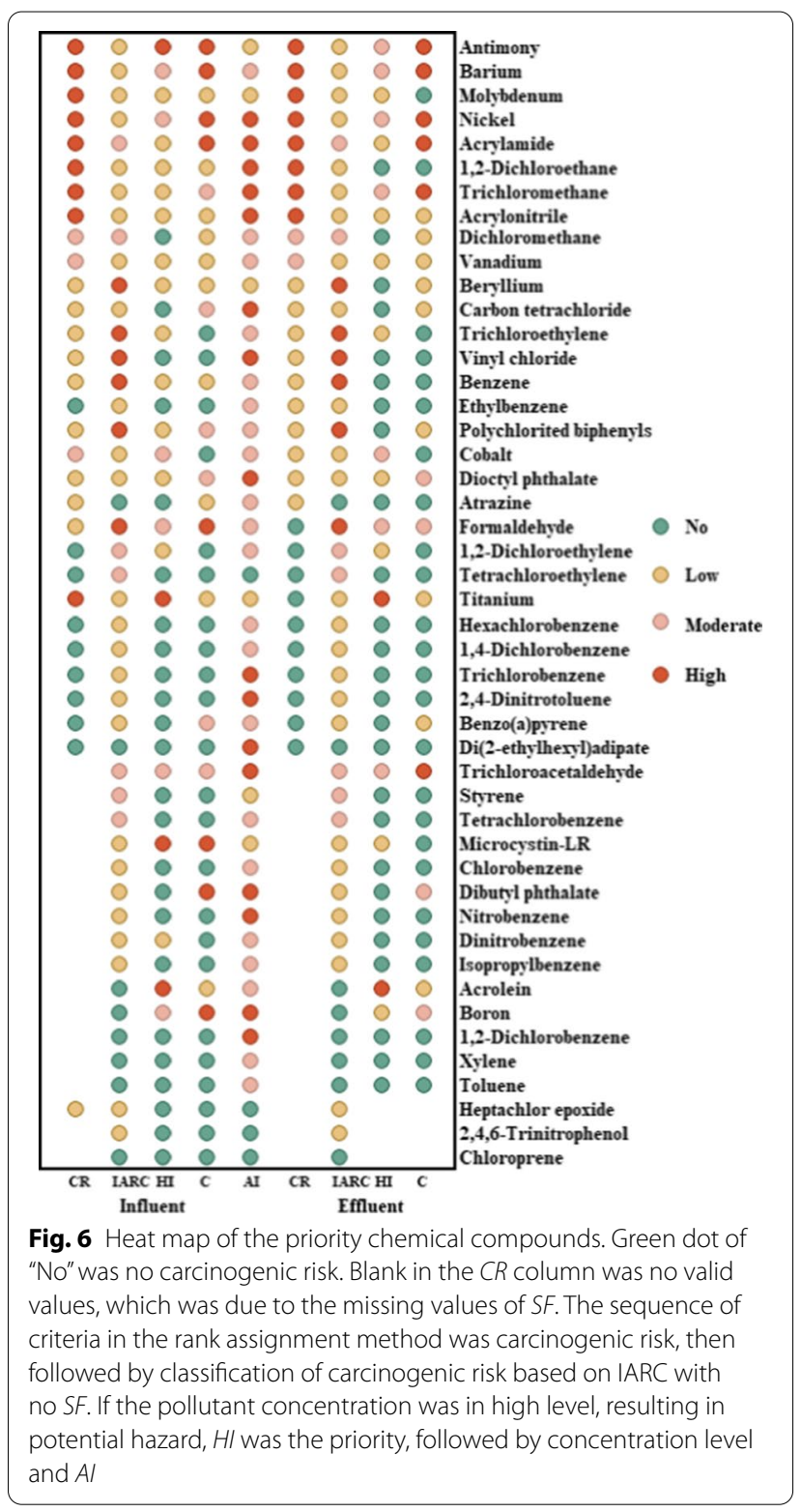

the concentration and carcinogenicity of the chemical compounds.

\section{Multiphasic evaluation of PCCs}

Figure 6 displayed a profile map of the chemical compounds in the influent and effluent. The screening of PCCs was first dependent on the rank of $C R$ values, then the classification of IARC and $H I$ values. Given the importance of carcinogenic risk on human health, the classification of IARC was secondly highlighted when the $S F$ values of chemicals were not found. Based on the above-mentioned criterion, 41 chemical compounds, except for 1,2-dichlorobenzene, toluene, xylene, 
heptachlor epoxide, 2,4,6-trinitrophenol, and chloroprene were considered as PCCs. The top eight chemical compounds (Sb, Ba, Mo, Ni, acrylamide, 1,2-dichloroethane, trichloromethane, and acrylonitrile) demonstrated a high carcinogenic risk connected to long-term drinking exposure. Tetrachloroethylene, 1,2-dichloroethylene, hexachlorobenzene, 1,4-dichlorobenzene, trichlorobenzene, 2,4-dinitrotoluene, benzo(a)pyrene and di(2-ethylhexyl)adipate demonstrated no carcinogenic risk in this study. The $H I$ values of formaldehyde and acrolein were high, indicating that they were a potential health hazard and should be monitored closely. Removing 1,2-dichlorobenzene via treatment processes is challenging, and this compound can even be generated during the chlorine disinfection process through free radical reactions $[13,58]$.

Comprehensive assessments, including the evaluation of treatment processes through $A I$ values, should be accounted for the screening of prior pollutants, which can promote the drinking water supply sector to attach importance to purification technologies. Non-carcinogenic $\mathrm{B}$ is harmful to human health at a high concentration, even if it is only detected in trace amounts in the human body. Barium, B, and V are not included in the PCCs list of both the United States and China [69]. However, these substances were detected at relatively high carcinogenic risk or potential hazard, indicating that they should be monitored. Given the scientific management of chemical compounds and the development of environmental sustainability, we introduced the concentrations of substances to the evaluation method. Dibutyl phthalate and di(2-ethylhexyl) phthalate are two common plasticizers for microplastics that have attracted negligible attention in previous studies. These substances and their metabolites have been proven to influence the endocrine system of the human body [70-72]. Due to its high $A I$ values, the safety of microplastics will become the future focus and attract much attention.

\section{Management suggestions for PCCs}

The above-mentioned results implied that the multiphasic assessment of chemicals by process control and health risk was comprehensive for the screening PCCs. The standard values of some chemical compounds should be re-modified, such as Mo and 1,2-dichloroethane. $C R$ values suggested that even an acceptable concentration was lower than the standard values in the effluent, which still threatened human health. To meet the DWS, modifying the standard values is one of the most important measures. Effective steps were suggested to keep a safe drinking concentration of pollutants in the effluent, such as protecting the raw water from pollution, introducing new advanced treatment technologies, and strengthening the removal performance of the drinking water treatment processes. Among these motions, protecting raw water from pollution is an indicative premise of the water environment and ecosystem health. The specific measure including the division of water source protection zones, is primary for the management of DWS in the government sector.

The dynamics of PCCs with the above-mentioned treatment processes implied that processes in the treatment of drinking water could be of great significance for process control and sustainable management. Thus, reliable and effective techniques used to increase DWS could facilitate the optimization of the purification process in DWTPs. Improving the removal performance during the purification process and reducing the generation of DBPs by introducing new advanced treatment technologies are suggested to be explored in future research for intensifying DWS and the sustainability of human health.

Last but not least, emerging pollutants (i.e., antibiotics, endocrine-disrupting chemicals and microplastics) should also be taken into consideration in the screening of PCCs. Occurrence (concentration), the performance on process control, health exposure and carcinogenic risk via an exhaustive evaluation for screening the PCCs is necessary for strengthening the optimization of process control and management of DWS. Moreover, with the continuous development of monitoring technology and the requirement of public health, more attention should be paid to the emerging pollutants and synchronous evaluation systems.

\section{Conclusions}

In the present study, we developed a novel multiphasic evaluation by simple rank assignment analysis, which could be used for selecting PCCs by process control and health risk in drinking water. The effluent concentrations, removal performance, non-carcinogenic health hazard, classification of carcinogens and carcinogenic risk were selected as multi-process indicators. Among the 76 monitored chemicals, 47 and 44 chemical compounds were detected in the influent and effluent, respectively. The difference between raw and treated water implied that many chemical compounds could be removed during the treatment processes. By-products were generated during purification and disinfection processes through synthesis, transformation, and degradation due to chemical reactions or biochemical reactions. The assessment result illustrated that the top eight PCCs with high carcinogenic risk were highlighted. Among the detected chemical compounds, the profiles of 41 contaminants could be scientifically applied to select PCCs targets. However, some emerging contaminants (i.e., antibiotics, microplastics, and endocrine-disrupting chemicals) have not 
been evaluated in this study. More on-site investigations on the emerging pollutants should be carried out in the future for the human health and management of DWS.

Finally, some effective measures should be implemented to ensure drinking concentrations of chemical pollutants in the effluent safety, such as protecting the raw water from contamination, enhancing removal performance and reducing by-products by introducing new advanced treatment technologies during the purification process. Collectively, the multiphasic assessments of PCCs provided a novel method and scientific support of process control to strengthen the sustainable management of source water and DWS.

\section{Supplementary Information}

The online version contains supplementary material available at https://doi. org/10.1186/s12302-021-00566-z.

Additional file 1. Additional information about supplementary data were list in the tables.

\section{Acknowledgements}

We thank Prof. Ma Liping for valuable comments that helped improve the quality of this work.

\section{Authors' contributions}

YL: conceptualization, writing — original draft, validation, project administration, funding acquisition; XL: sampling, analyzing, methodology, investigation, data curation, validation; XQ: methodology, investigation, data curation, validation; XZ: methodology, investigation, data curation; SG: investigation; data curation; validation; HW: writing — original draft, validation, project administration; DL: conceptualization, formal analysis, analyzing, investigation, methodology, data curation, writing - original draft, validation. All authors read and approved the final manuscript.

\section{Funding}

This study was financially supported by the National Water Pollution Control and Treatment Science and Technology Major Project (No. 2017ZX07401004).

\section{Availability of data and materials}

All data generated or analyzed during this study are included in this published article

\section{Declarations}

Ethics approval and consent to participate

Not applicable.

\section{Consent for publication}

Not applicable.

\section{Competing interests}

The authors declare that they have no conflicts of interest that influenced the work reported in this study.

\section{Author details}

${ }^{1}$ Environmental Standard Institute, Ministry of Ecology and Environment of the People's Republic of China, Chinese Research Academy of Environmental Sciences, 100012 Beijing, China. ${ }^{2}$ State Key Laboratory of Environmental Criteria and Risk Assessment, Chinese Research Academy of Environmental Sciences, Beijing 100012, China.
Received: 18 June 2021 Accepted: 23 October 2021

Published online: 12 January 2022

\section{References}

1. Gerlak AK, House-Peters L, Varady RG, Albrecht T, Zúñiga-Terán A, de Grenade RR, Cook C, Scott CA (2018) Water security: a review of place-based research. Environ Sci Policy 82:79-89

2. Prasai T, Lekhak B, Joshi DR, Baral MP (2007) Microbiological analysis of drinking water of Kathmandu Valley. Sci World 5(5):112-114

3. Bari MA, Kindzierski WB (2018) Ambient volatile organic compounds (VOCs) in Calgary, Alberta: sources and screening health risk assessment. Sci Total Environ 631:627-640

4. Srinivasan R, Sorial GA (2011) Treatment of taste and odor causing compounds 2-methyl isoborneol and geosmin in drinking water: a critical review. J Environ Sci 23(1):1-13

5. Yousefi M, Ghalehaskar S, Asghari FB, Ghaderpoury A, Dehghani MH, Ghaderpoori M, Mohammad AA (2019) Distribution of fluoride contamination in drinking water resources and health risk assessment using geographic information system, northwest Iran. Regul Toxicol Pharmacol 107:104408

6. Bu Q, Wang D, Wang Z (2013) Review of screening systems for prioritizing chemical substances. Crit Rev Environ Sci Technol 43(10):1011-1041

7. Polyakova OV, Artaev VB, Lebedev AT (2018) Priority and emerging chemical compounds in the Moscow rain. Sci Total Environ 645:1126-1134

8. El-Shahawi M, Hamza A, Bashammakh A, Al-SaggafWJ (2010) An overview on the accumulation, distribution, transformations, toxicity and analytical methods for the monitoring of persistent organic pollutant. Talanta 80(5):1587-1597

9. Li H, Zhang J, You J (2018) Diagnosis of complex mixture toxicity in sediments: application of toxicity identification evaluation (TIE) and effectdirected analysis (EDA). Environ Pollut 237:944-954

10. Stuart M, Dan L, Crane E, Hart A (2012) Review of risk from potential emerging contaminants in UK groundwater. Sci Total Environ 416(2):1-21

11. Mas S, de Juan A, Tauler R, Olivieri AC, Escandar GM (2010) Application of chemometric methods to environmental analysis of organic chemical compounds: a review. Talanta 80(3):1052-1067

12. Ohe PC, Dulio V, Slobodnik J, Deckere E, Kühne R, Ebert R, Ginebreda A, Cooman WD, Schüürmann G, Bracka W (2011) A new risk assessment approach for the prioritization of 500 classical and emerging organic microcontaminants as potential river basin specific chemical compounds under the European Water Framework Directive. Sci Total Environ 409(11):2064-2077

13. Lee S, Guo H, Lam S, Lau S (2004) Multi-pathway risk assessment on disinfection by-products of drinking water in Hong Kong. Environ Res 94(1):47-56

14. Bodzek M, Konieczny K, Kwiecińska A (2011) Application of membrane processes in drinking water treatment-state of art. Desalin Water Treat 35(1-3):164-184

15. Krasner SW, Weinberg HS, Richardson SD, Pastor SJ, Chinn R, Sclimenti MJ, Onstad GD, Thruston AD (2006) Occurrence of a new generation of disinfection byproducts. Environ Sci Technol 40(23):7175-7185

16. Hrudey SE, Hrudey EJ, Pollard S (2006) Risk management for assuring safe drinking water. Environ Int 32(8):948-957

17. Li L, Rong S, Wang R, Yu SL (2021) Recent advances in artificial intelligence and machine learning for nonlinear relationship analysis and process control in drinking water treatment: a review. Chem Eng J 405:126673

18. Akiyama M, Matsui Y, Kido J, Matsushita T, Shirasaki N (2018) Monte-Carlo and multi-exposure assessment for the derivation of criteria for disinfection by-products and volatile organic compounds in drinking water: allocation factors and liter-equivalents per day. Regul Toxicol Pharmacol 95:161-174

19. Chen C, Zhang X, He W, Lu W, Han H (2007) Comparison of seven kinds of drinking water treatment processes to enhance organic material removal: a pilot test. Sci Total Environ 382(1):93-102

20. Hasan HA, Muhammad MH, Ismail N (2020) A review of biological drinking water treatment technologies for contaminants removal from polluted water resources. J Water Process Eng 33:101035 
21. Bu Q, Wang D, Liu X, Wang Z (2014) A high throughout semi-quantification method for screening organic contaminants in river sediments. J Environ Manag 143(1):135-139

22. Duong HT, Kadokami K, Pan S, Matsuura N, Nguyen TQ (2014) Screening and analysis of 940 organic micro-chemical compounds in river sediments in Vietnam using an automated identification and quantification database system for GC-MS. Chemosphere 107:462-472

23. GB3838-2002 (2002) Chinese National Environmental Quality Standards for Surface Water. Ministry of Ecology and Environment of the People's Republic of China, Beijing

24. Goodmana JE, Mayfield DB, Becker RA, Hartigan SB, Erraguntla NK (2020) Recommendations for further revisions to improve the International Agency for Research on Cancer (IARC) Monograph program. Regul Toxicol Pharmacol 113:104639

25. IARC (2002) Working group evaluation carcinogenic risks humans. International Agency for Research on Cancer (IARC) Monographs on the evaluation of carcinogenic risks to humans. IARC Monogr Eval Carcinog Risks Hum 80:273-338

26. Liu Y, Zheng B, Fu Q, Meng W, Wang YY (2009) Risk assessment and management of arsenic in raw water in China. J Hazard Mater 170:729-734

27. USEPA (1996) Proposed Guidelines for Carcinogen Risk Assessment. U.S. Environmental Protection Agency, Washington DC

28. USEPA (2002) Integrated Risk Information System (Electronic data base). U.S. Environmental Protection Agency, Washington DC

29. Ta N, Zhou F, Gao Z, Zhong M, Sun C (2006) The status of pesticide residues in the drinking water sources in Meiliangwan Bay, Taihu Lake of China. Environ Monit Assess 123(1):351-370

30. Abdolahnejad A, Gheisari L, Karimi M, Norastehfar N, Ebrahimpour K, Mohammadi A, Ghanbari R, Ebrahimi A, Jafari NJ (2019) Monitoring and health risk assessment of phthalate esters in household's drinking water of Isfahan. Int J Environ Sci Technol 16(11):7409-7416

31. Caron-Beaudoin É, Valter N, Chevrier J, Ayotte P, Frohlich K, Verner MA (2018) Gestational exposure to volatile organic compounds (VOCs) in Northeastern British Columbia, Canada: a pilot study. Environ Int 110:131-138

32. Gou LF, Jin Z, Galy A, Gong YZ, Nan XY, Jin CY, Wang XD, Bouchez JL, Cai HM, Chen JB, Yu HM, Huang F (2020) Seasonal riverine barium isotopic variation in the middle Yellow River: sources and fractionation. Earth Planet Sci Lett 531:115990

33. Kong P, Cheng $X$, Sun $R$, Chen $L$ (2018) The synergic characteristics of surface water pollution and sediment pollution with heavy metals in the Haihe River Basin Northern China. Water 10(1):73

34. Liang B, Han G, Liu M, Yang KH, Li XQ, Liu JK (2018) Distribution, sources, and water quality assessment of dissolved heavy metals in the Jiulongjiang River water, Southeast China. Int J Environ Res Public Health 15(12):2752

35. Wu J, Man Y, Sun G, Shang LH (2018) Occurrence and health-risk assessment of trace metals in raw and boiled drinking water from rural areas of China. Water 10(5):641

36. Bai M, Huang X, Zhong Z, Cao MJ, Gao M (2019) Comparison of OH and $\mathrm{NaClO}$ on geosmin degradation in the process of algae colonies inactivation at a drinking water treatment plant. Chem Eng J 393:123243

37. Sun S, Jiang T, Lin Y, Song J, Zheng YY, An D (2020) Characteristics of organic pollutants in source water and purification evaluations in drinking water treatment plants. Sci Total Environ 733:139277

38. Yu Y, Ma X, Chen RY, Li GW, Tao H, Shi BY (2019) The occurrence and transformation behaviors of disinfection byproducts in drinking water distribution systems in rural areas of eastern China. Chemosphere 228:101-109

39. Matoso V, Bargi-Souza P, Ivanski F, Romano MA, Romano RM (2019) Acrylamide: a review about its toxic effects in the light of Developmental Origin of Health and Disease (DOHaD) concept. Food Chem 283:422-430

40. Wang RM, Ji M, Zhai HY, Liu Y (2020) Occurrence of phthalate esters and microplastics in urban secondary effluents, receiving water bodies and reclaimed water treatment processes. Sci Total Environ 737:140219

41. Zhu QQ, Jia JB, Zhang KG, Zhang H, Liao CY (2019) Spatial distribution and mass loading of phthalate esters in wastewater treatment plants in China: an assessment of human exposure. Sci Total Environ 656:862-869

42. Ye X, Wang P, Wu Y, Zhou Y, Sheng Y, Lao K (2020) Microplastic acts as a vector for contaminants: the release behavior of dibutyl phthalate from polyvinyl chloride pipe fragments in water phase. Environ Sci Pollut Res 27(33):42082-42091

43. Koelmans AA, Nor NHM, Hermsen E, Kooi M, Mintenig SM, France JD (2019) Microplastics in freshwaters and drinking water: critical review and assessment of data quality. Water Res 155:410-422

44. Kadokami K, Li X, Pan S, Ueda N, Hamada K, Jinya D, Iwamura T (2013) Screening analysis of hundreds of sediment chemical compounds and evaluation of their effects on benthic organisms in Dokai Bay, Japan. Chemosphere 90(2):721-728

45. Camel V, Bermond A (1998) The use of ozone and associated oxidation processes in drinking water treatment. Water Res 32(11):3208-3222

46. Ormad MP, Miguel N, Claver A, Matesanz JM, Ovelleiro JL (2008) Pesticides removal in the process of drinking water production. Chemosphere 71(1):97-106

47. Mazhar MA, Khan NA, Ahmed S, Khan AH, Rahisuddin HA, Changani F, Yousefi M, Ahmadi S, Vambol V (2020) Chlorination disinfection byproducts in Municipal drinking water-a review. J Clean Prod 273:123159

48. Mian HR, Hu G, Hewage K, Rodriguez MJ, Sadiq R (2018) Prioritization of unregulated disinfection by-products in drinking water distribution systems for human health risk mitigation: a critical review. Water Res 147:112-131

49. Singer PC (1994) Control of disinfection by-products in drinking water. J Environ Eng 120(4):727-744

50. Mohammadi L, Rahdar A, Bazrafshan E, Dahmardeh H, Thysiadou A, Kyzas GZ (2021) Benzene removal from aqueous solutions by heterogeneous catalytic ozonation process with magnesium oxide nanoparticles. Ozone 43(2):147-162

51. Shen Y, Zhu C, Chen J, Fang Q, Chen W, He Z, Xu H, Song S (2020) A hybrid block consisting of covalent triazine frameworks and GO aerogel with switchable selectivity between adsorption of UV filters and regeneration under sunlight. Chem Eng J 395:125074

52. Ma S, Guo X, Chen B (2016) Toward better understanding of chloral hydrate stability in water: kinetics, pathways, and influencing factors. Chemosphere 157:18-24

53. Zhang S, Wang X, Yang H, Xie YF (2016) Chlorination of oxybenzone: kinetics, transformation, disinfection byproducts formation, and genotoxicity changes. Chemosphere 154:521-527

54. Adewale OO, Brimson JM, Odunola OA, Gbadegesin MA, Owumi SE, Isidoro C, Tencomnao T (2015) The potential for plant derivatives against acrylamide neurotoxicity. Phytother Res 29(7):978-985

55. Chaves RS, Guerreiro CS, Cardoso VV, Benoliel M, Santos MM (2019) Hazard and mode of action of disinfection by-products (DBPs) in water for human consumption: evidences and research priorities. Comp Biochem Physiol C 223:53-61

56. Li XF, Mitch WA (2018) Drinking water disinfection byproducts (DBPs) and human health effects: multidisciplinary challenges and opportunities. Environ Sci Technol 52:1681-1689

57. Llorca M, Lucas D, Ferrando-Climent L, Badia-Fabregat M, Cruz-Morató C, Barceló D, Rodríguez-Mozaza S (2016) Suspect screening of emerging chemical compounds and their major transformation products in wastewaters treated with fungi by liquid chromatography coupled to a high-resolution mass spectrometry. J Chromatogr A 1439:124-136

58. Mishra BK, Gupta SK, Sinha A (2014) Health risk analysis from disinfection by-products (DBPs) in drinking and bathing water of some Indian cities. J Environ Health Sci Eng 12(1):1-10

59. Tang M, Wang H, Hu Y, Chen W, Akao FZ (2011) Acrolein induced DNA damage, mutagenicity and effect on DNA repair. Mol Nutr Food Res 55(9):1291-1300

60. Leong TY, Leong AS (2005) Epidemiology and carcinogenesis of hepatocellular carcinoma. HPB 7:5-15

61. Zhou L, Yu H, Chen K (2002) Relationship between microcystin in drinking water and colorectal cancer. Biomed Environ Sci 15:166-171

62. Chen L, Giesy JP, Xie P (2018) The dose makes the poison. Sci Total Environ 621:649-653

63. Saoudi A, Brient L, Boucetta S, Ouzrout R, Bormans M, Bensouilah M (2017) Management of toxic cyanobacteria for drinking water production of Ain Zada Dam. Environ Monit Assess 189(7):1-11

64. Wang Q, Niu Y, Xie P, Chen J, Ma Z, Tao M, Qi M, Wu L, Guo L (2010) Factors affecting temporal and spatial variations of microcystins in Gonghu Bay of Lake Taihu, with potential risk of microcystin contamination to human health. Sci World J 10:1795-1809 
65. Oliveira EDC, Castelo-Branco R, Silva L, Silva M, Azevedo J, Vasconcelos V, Faustino S, Cunha A (2019) First detection of microcystin-LR in the amazon river at the drinking water treatment plant of the municipality of Macapá, Brazil. Toxins 11(11):669

66. Li Z, Chang F, Shi P, Chen X, Yang F, Zhou Q, Pan Y, Li A (2018) Occurrence and potential human health risks of semi-volatile organic compounds in drinking water from cities along the Chinese coastland of the Yellow Sea. Chemosphere 206:655-662

67. Kim KH, Jahan SA, Lee JT (2011) Exposure to formaldehyde and its potential human health hazards. J Environ Sci Health Part C Environ Carcinog Rev 29(4):277-299

68. Wang X, Mao Y, Tang S, Yang HW, Xie YF (2015) Disinfection byproducts in drinking water and regulatory compliance: a critical review. Front Environ Sci Eng 9(1):3-15

69. Sullivan PJ, Agardy FJ, Clark J (2005) The Environmental Science of Drinking Water, 1st edn. Elsevier, Amsterdam

70. Galloway TS (2015) Micro-and nano-plastics and human health. Marine anthropogenic litter. Springer International Publishing, New York, pp 343-366

71. Horton AA, Walton A, Spurgeon DJ, Lahive E, Svendsen C (2017) Microplastics in freshwater and terrestrial environments: evaluating the current understanding to identify the knowledge gaps and future research priorities. Sci Total Environ 586:127-141

72. Jaimes R, Swiercz A, Sherman M, Muselimyan N, Marvar P, Posnack NG (2017) Plastics and cardiovascular health: phthalates may disrupt heart rate variability and cardiovascular reactivity. AJP Heart Circ Physiol 313(5):1044-1053

\section{Publisher's Note}

Springer Nature remains neutral with regard to jurisdictional claims in published maps and institutional affiliations.

\section{Submit your manuscript to a SpringerOpen ${ }^{\odot}$ journal and benefit from:}

- Convenient online submission

- Rigorous peer review

- Open access: articles freely available online

- High visibility within the field

- Retaining the copyright to your article

Submit your next manuscript at $\mathbf{s p r i n g e r o p e n . c o m ~}$ 